\title{
Breast Feeding Practices among the Hakkipikkis: A Tribal Population of Mysore District, Karnataka
}

\author{
B. Dakshayani and M. R. Gangadhar \\ Department of Anthropology, University of Mysore, Manasagangotri, \\ Mysore 570 006, Karnataka, India \\ E-mail: gangadharmr@yahoo.com
}

KEYWORDS Breastfeeding. Pre-Lacteal Food. Colostrum. Pakshirajpura

\begin{abstract}
The practice of breast-feeding is almost universal. In the present study, an attempt was made to understand various aspects of feeding practices among the Hakkipikkis of Mysore district of Karnataka state. One hundred and twenty five (125) mothers were interviewed personally on breast feeding practices such as Initiation of Breast-feeding, Duration of Breast feeding, Introduction of pre-lacteal feed and Supplementary feeding practices etc.
\end{abstract}

\section{INTRODUCTION}

Mother's milk is the nature's gift to the baby. Breast milk is the ideal food for all infants and provides adequate nutritional requirements up to the age of five months. Breast feeding lay the foundation for their healthy psychosocial development, besides providing perfect nutrition for infants. The health and nutritional status of millions of infants influence their subsequent growth and development throughout childhood is determined by the patterns of feeding during the infancy.

Traditionally it has been believed that breast feeding is the best form of infant feeding which ensures optimum growth, enhances intellectual and emotional development and improves child survival by providing protection against infections, diseases and malnutrition for infant (Singh et al., 1992). The composition of breast milk undergoes change in quality to meet nutritional and immunological needs of the baby at different stages of child growth.

Many pioneering works on breast feeding have been undertaken by various medical and social scientists (Behl, 1979; Narayana, 1983; Das and Ghosh, 1985; Swain, 1985; Bhan, et al., 2004; Dash and Choudhury 2005). Many studies have been undertaken on breast feeding in various tribal population of the world. Still there are many communities left untouched. The present work is an attempt to add some more knowledge about breast feeding practices among Hakkipikkkis of Mysore district of Karnataka state.

\section{METHODOLOGY}

The sample for the study comprises of 125 mothers in the age group of 17 to 35 years, belonging to Pakshirajpura of Hunsur taluk of Mysore district, Karnataka state. Data were collected during September to December 2006. Mothers of the children (0-60 months) were interviewed using a pre-designed structured questionnaire. Interview schedule comprised of socio-economic background of the family of the child, care during pregnancy and delivery, care of nursing mothers, feeding and weaning practices, personal cleanliness, healthcare, play, sleep and rest, toilet training, socialization etc.

For the present study, Information regarding Initiation of Breast feeding, Duration of Breast feeding, Pre-lacteal feed and age of supplementation were recorded. The questions asked during field work were: a) when does baby lactated for the first time b) How long breast feeding was done c) Does any prelacteal food given d) when was the supplementary/weaning food introduced to infants etc.

\section{RESULTS AND DISCUSSION}

Details of initiation of breast feeding are shown in Table 1 . Nearly 76 percent mothers said they breastfed their child immediately after birth. It was seen that majority of mothers fed colostrum. While 20 percent of the mothers reported that they initiate breast feeding on the $2^{\text {nd }}$ day, and 4 percent on $3^{\text {rd }}$ day of the birth of the child. The reason for not feeding colostrum in rest of the mothers ( 24 percent) was traditional belief, 
Table 1: Initiation of breast feeding

\begin{tabular}{llrc}
\hline S. & $\begin{array}{l}\text { Initiation of } \\
\text { Noreast feeding }\end{array}$ & No. & Percentage \\
\hline 1 & Immediately after birth & 95 & 76.0 \\
2 & Second day of the birth & 25 & 20.0 \\
3 & Third day of the birth & 05 & 4.0 \\
\hline Total & & 125 & 100.0 \\
\hline
\end{tabular}

as they considered it thick, cheesy, indigestible, unhygienic and not good for the baby.

This shows that doctors are creating awareness among mothers regarding infant feeding practices. Still there is a need of intensive breast feeding education to mothers for removing various myths regarding breast feeding.

Das and Ghosh (1985) found that breast feeding was the main form of food for the infants among the santals of Bihar. Bhan et al. (2004) conducted a comparative study of Breast-feeding practices among Kashmiri pandits and Dogras and found that although breast feeding was started on the first day, 90 percent mothers of both the communities discarded the initial milk (colostrum) as harmful and impure. So only a part of it was fed to the infants.

Dash and Choudhury (2005) reported about breast feeding practices among Santals and non Santals of Orissa. The results show that almost 37.78 percent of santal babies and 48 percent of non santal babies were first put to breast with in 6 hours after birth. Majority of the santal mothers $(53.13 \%)$ did not give colostrum where as 66 percent of non santal mothers fed with colostrum.

Table 2 shows the duration of breast feeding. About 76 percent of the mother's breast fed their children upto one year and above, while $20.08 \%$ of mothers fed their children up to 9 months and 3.02 percent of them breast fed up to 2 years. It appears that tribal children in the studied population enjoy the precious gift of nature for a long period.

Behl (1979) reported about infant feeding practices among the tribals of Himachal Pradesh, the results showed that 84 percent of the children were given their first fed 12 hours after birth

Table 2: Duration of breast feeding

\begin{tabular}{llrr}
\hline S. & $\begin{array}{c}\text { Duration of } \\
\text { breast feeding }\end{array}$ & No. & Percentage \\
\hline 1 & 9 months & 26 & 21.0 \\
2 & 1 year and above & 95 & 76.0 \\
3 & 2 years & 04 & 3.0 \\
\hline Total & & 125 & 100.00 \\
\hline
\end{tabular}

and most mothers breast fed their children up to 36 months.

The practice of giving the infants some special type of feeds before initiating breast milk is widespread in tribal areas. Practically colostrum alone is sufficient to maintain the nutritional demand of the newborns during prelacteal stage of the mothers without any type of prelacteal feeds (Talukder et al., 1992). On the other hand introduction of prelacteal feed often resulted in "insufficient milk syndrome" and leads the newborn to the risk of infection especially diarrheal diseases (Akhter, 1992). It was the reflection of their ignorance about the nutritional value of colostrum at the one hand and ill effect of pre-lacteal foods on the other.

Table 3 shows the introduction of prelacteal feed. Sugar water (29\%) was on the top of the list of the pre-lacteal foods followed by milk mixed with Jaggery (9\%), Honey (6\%), Hot water mixed with sugar or Jaggery (3\%), Milk mixed with sugar $(3 \%)$. While $60 \%$ of the mothers did not use prelacteal foods. Many women reported that, these prelacteal feeds were given as cleansing agents. These prelacteal feeds interfere with the suckling stimulation and prolactin production, but also often these feeds are the source of infection to the newborns.

Table 3: Introduction of pre-lacteal feed

\begin{tabular}{llrc}
\hline S. & Pre-lacteal & No. & Percentage \\
No. & feed introduced & 75 & 60.0 \\
\hline 1 & No & 29 & 23.2 \\
2 & Sugar water & 9 & 7.2 \\
3 & Milk mixed with Jaggery & 3 & 2.4 \\
4 & Hot water mixed with & & \\
& sugar or jaggery & 6 & 4.8 \\
5 & Honey & 3 & 2.4 \\
6 & Milk mixed with sugar & 125 & 100.0 \\
\hline Total & & & \\
\hline
\end{tabular}

Swain (1985) studied the infant feeding practices among santal tribe in northern Orissa and found that immediately after the child's birth, honey or jaggery was given to the child. Which they believe, could help the child resist hunger. The child was usually put to breast after 12 hours. The supplementary feeding to the baby started when the child reached the age of seven months.

The right time of introducing semi-solid or solid food to the baby's diet, supplementing right type of food in right amount and the frequency of feeding, that is, number of times children are fed in a day are most crucial factors to be consid- 
ered for appropriate infant and child feeding practices.

Information regarding the practices associated with supplementary feeding of the child is presented in Table 4. The growing child requires supplementary feeding besides breast feeding. The initiation of supplementary feeding at appropriate timing is important, which is generally recommended as 4-6 months age of the child. In the present study, nearly $48 \%$ are initiating the supplementary feeding during $6^{\text {th }}$ to $9^{\text {th }}$ month. Followed by those giving in $4^{\text {th }}$ to $6^{\text {th }}$ month $(26.4 \%), 12^{\text {th }}$ month $(11.2 \%)$. In 9th to $12^{\text {th }}$ month and after $12^{\text {th }}$ month the percentage $(7.2 \%)$ of feeding supplementary food is found to be same.

Table 4: Age of starting supplementary food

\begin{tabular}{llrc}
\hline S.No. & Age & No. & Percentage \\
\hline 1 & $4-6$ month & 33 & 26.4 \\
2 & $6-9$ month & 60 & 48.0 \\
3 & $9-12$ month & 9 & 7.2 \\
4 & $12^{\text {th }}$ month & 14 & 11.2 \\
5 & After $12^{\text {th }}$ month & 9 & 7.2 \\
\hline Total & & 125 & 100.0 \\
\hline
\end{tabular}

Narayan (1983) studied the health care of the oraon children from the Barambe village in Ranchi district, Bihar and found that the oraon child totally dependent on mothers milk till the age of one year. After the completion of a year the baby was given solid food.

So it was found that although people have become aware of the importance of breast feeding but still there is a great need for intensive nutrition education programme in this context.

\section{REFERENCES}

Akhter, H. 1992. "Breast feeding practices in Bangladesh." Bangladesh J. Child Health, 16(1/ 2): 31-35.

Behl, L. 1979. "Some aspects of infant rearing practices and beliefs of tribal inhabitants of Himachal Pradesh." Indian Pediatrics, 16 (4): 337-341.

Bhan, Nirojini Bhat, Payal Mahajan and Bandana, Bhadwal. 2004. "A comparative study of Breast feeding practices among Kashmiri Pandits and Dogras." Anthropologist, 6(4): 261-263.

Das, K. and A.K. Ghosh. 1985. "Child health care: a study on the Santhals of Bihar," (pp.148-152) in B Chaudhuri (ed.), Tribal Health: Socio-cultural Dimensions. New Delhi: Inter India Publications.

Dash, Malini and R.K. Choudhury. 2005. "Breast feeding practices among Santals and non Santals of Orissa." Anthropologist, 7(4):283-287.

Narayan, S. 1983. "Health care of the Oraon children." Social Welfare, XXX(1): 17-18.

Swain, L. 1985. "Santal tribes: Infant feeding practices." Social Welfare, XXXII(3): 22-23.

Singh, R., O.A. Kumar and R.S. Rana. 1992. "Breast feeding and weaning practices among urban Muslims of district Lucknow." Ind. Ped., 31: 352-364.

Talukder, Mq-K., S.M. Kabir and S. Talukder. 1992. "Problems in Breast feeding and their management." Bangladesh J. Child Health, 16(1/2): 37-48. 